$1986,35,1$

УдК 552.124.3(474.2)

Mape $\mathrm{KOHCA}$

\title{
ТИПОМОРФНЫЕ ОСОБЕННОСТИ ЦИРКОНА ПОРОД КРИСТАЛЛИЧЕСКОГО ФУНДАМЕНТА ЭСТОНИИ
}

Результаты геолого-петрографического изучения кристаллического фундамента обобщены в недавно вышедшей монографии (Кристаллический ..., 1983). Исследования акцессорных минералов в породах фундамента, однако, освещены недостаточно.

Автором в течение ряда лет изучались акцессорные минералы из характерных петрографических типов пород фундамента Северной Прибалтики. В частности, изучены метаморфические и ультраметаморфнческие породы архейских структур Южной и Западной Эстонии и Тапаского и Иыхвиского блоков, свекофеннских складчатых зон (Таллинской, Алутагузеской) и постсвекофеннских гранитных массивов (таблица) (Кристаллический ..., 1983, рис. 1, 2).

В настоящей статье обобщены результаты изучения типоморфизма циркона почти 80 проб. Пробы отбирали из свежих невыветрелых интервалов керна скважин и характерных типов пород, исходя из детальных геолого-петрографических описаний, составленных по данным макро- и микроскопических исследований геологами X. Коппельмаа, M. Нийн и др. Пробы кристаллических пород дробили, обогащали в тяжелой жидкости (бромоформ), иммерсионные препараты изготавливали из класса $0,1-0,05$ мм. Характеристика типоморфизма обычно составлялась на основе 500 зерен из каждой пробы, при малой встречаемости циркона - не менее 200 зерен.

\begin{tabular}{c|c|c|c}
\hline \multirow{2}{*}{$\begin{array}{c}\text { № } \\
\text { пп }\end{array}$} & Породы & Типоморфные разновндности циркона \\
\cline { 3 - 3 } & & Главные & Второстепенные \\
\hline 1 & 2 & 3 & 4 \\
\hline
\end{tabular}

Архейские метаморфические породы

1. Биотит-амфиболпироксеновые и двупироксеновые гнейсы, архей, Южная Әстония (скв. 173)

2. Гранитогнейсы, Южная Эстония (скв. 423,555$)$

3. Бнотит-амфиболовые гнейсы, архей, Тапаский блок (скв. Ф-159)
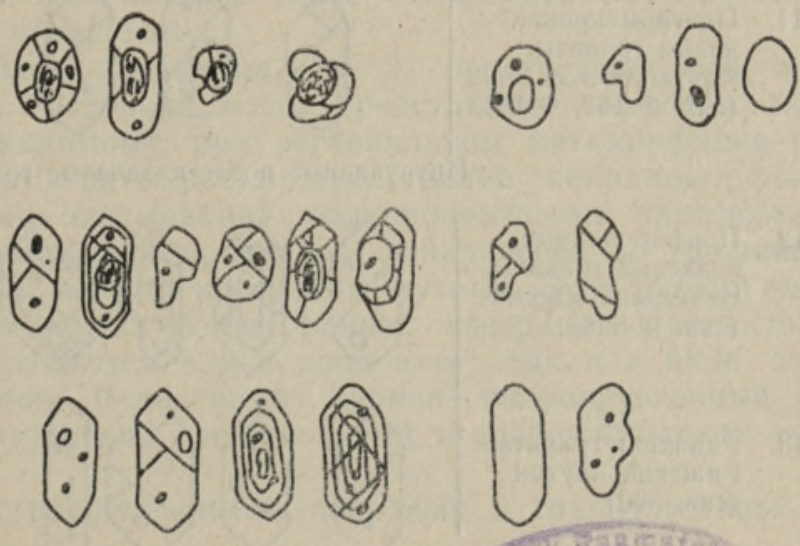
Нижнепротерозойские метаморфические породы

4. Амфиболнты, нижннй протерозой, Алутагузеская зона (скв. Ф-147)

5. Биотитовые плагиогнейсы, нижний протерозой Таллинской зоны (скв. Ф-129)

6. Глиноземистые гнейсы и биотитовые гнейсы, нижний протерозой, Алутагузеская зона (скв. Ф-144, Ф-154, $\Phi-147, \Phi-150$, Ф-156, Ф-146
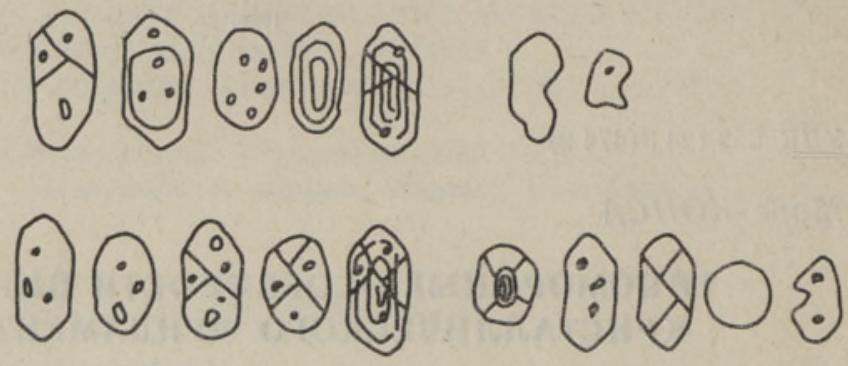

7. Чарнокиты, архей, Южная Эстония (скв. 555)

Чарнокиты и мигматитобразующие граниты

8. Теневые граниты, теневые мигматиты, Тапаский блок (скв. Ф-164)

9. Теневые граниты, теневые мигматиты, Пыхвиский блок (скв. Ф-169)

10. Плагиограниты, Алутагузеская зона (сКВ. Ф-163)

11. Плагиомикроклиновые граниты, Алутагузеская зона (скв. Ф-161, Ф-168)
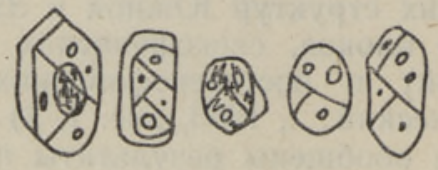

80
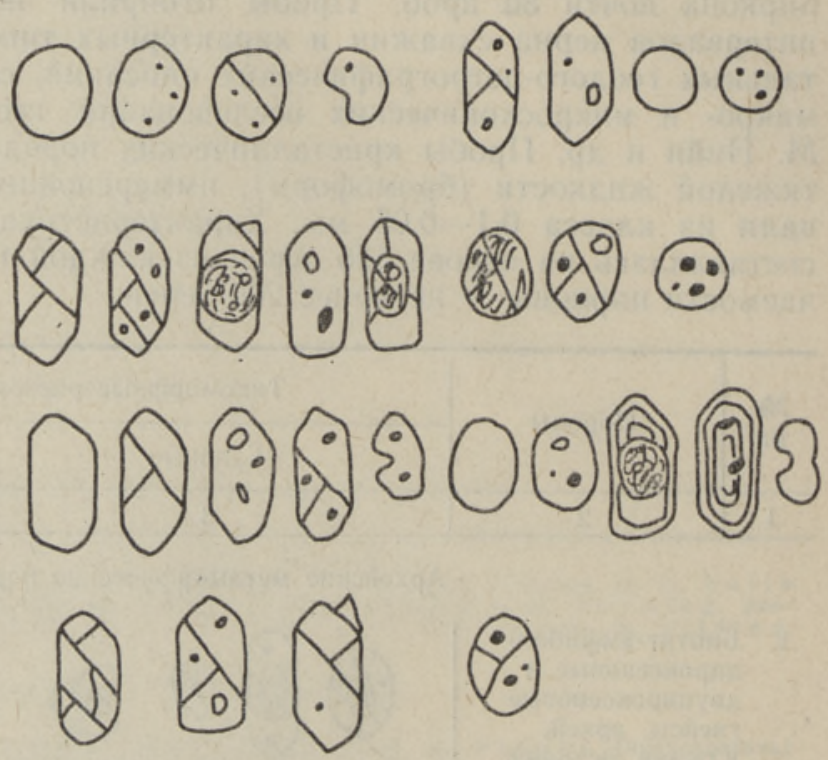

Интрузивные послескладчатые граниты

12. Порфировидные калиевые граниты, Неэмеский массив (скв. Ф-508)

13. Рапакиви-граниты, Рижский плутон (скв. 500)
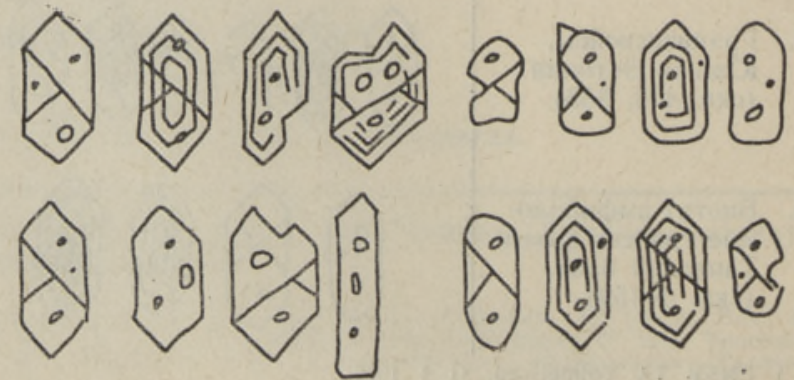
Исследование цирконов пород кристаллического фундамента проводилось с целью установить общие особенности его типоморфизма в связи с выяснением вопросов происхождения обломочных цирконов перекрывающих вендских и кембрийских терригенных осадочных пород (Конса, Вийдинг, 1983; Вийдинг, Конса, 1976). Одновременно было установлено, что некоторые специфические особенности типоморфизма циркона могут оказаться значимыми для выяснения генезиса самих пород фундамента. Так, учитывая результаты исследований цирконов в соседнем регионе (Вайтекунас, Васильев, 1975) и обобщающие работы В. В. Ляховича (1979) и др., на основе проведенного нами исследования представляет интерес наличие или отсутствие в породах: 1) окатанных (обломочных) цирконов, как надежного критерия осадочного происхождения пород, 2) зональных кристаллов циркона, вероятно формировавшихся в ходе метаморфизма, 3) идиоморфных или панидиоморфных кристаллов с совершенной огранкой, как индикаторов магматических гранитов и др.

Ниже приводится краткая характеристика типоморфизма цирконов в породах, сгруппированных по возрасту, структурной позиции и генезису, в соответствии с принятыми схемами расчленения (Кристаллический ..., 1983).

\section{Архейские метаморфические породы}

В биотит-амфибол-пи роксеновых и двупироксенов ы х г ней с ах (таблица, № 1) форма зерен циркона в той или иной степени округленная. По характеру округленности можно выделить три типа зерен.

Первый тип - панидиоморфный циркон (до $26 \%$ от количества зерен в пробе). Характер граней кристаллов можно определить, но их вершины и ребра носят явные следы окатывания. Кристаллы трещиноватые, разломанные, часто непрозрачные, содержат большое количество включений и полуокругленные (часто близкие к панидиоморфным) ядра более темноокрашенного циркона.

Второй тип - циркон в виде полуокругленных кристаллов (до $50 \%$ ). Кристаллы темноокрашенные, мутные, сильно трещиноваты и содержат много включений.

Третий тип - обломки кристаллов со следами окатывания на
краях.

В рассматриваемых породах часто наблюдаются своеобразные «бесформенные» (как будто агрегатные) кристаллы. Такой грануломорфный рост (Краснобаев, Сплошнова, 1971) - это начальная стадия формирования собственного (в отличие от кластогенного) циркона в гнейсах. По мнению этих авторов такие «бесформенные» кристаллы постепенно переходят в округлые.

В гранитогнейс ах (таблица, № 2) присутствует три типа (генерации) цирконов. Основная масса представлена цирконом, который образовался, по-видимому, при региональном метаморфизме гранулитовой фации. Этот тип 'циркона представлен панидиоморфными (но с явными следами окатывания) полупрозрачными кристаллами. Довольно четко в кристаллах проявлена зональность и трещиноватость, много включений, иногда кристаллы мутные. Этот циркон часто образует оболочки на зернах более ранней генерации (реликтовый циркон), которые встречаются как в виде ядер, так и в виде самостоятельных кристаллов. Реликтовый циркон полуокругленный или округленный, полупрозрачный, трещиноватый и содержит много вклю. чений.

По сравнению с вышеописанными породами в гранитогнейсах не- 
сколько больше новообразованного циркона (более поздняя генерация), возникновеңие которого (по-видимому) связано с метасоматозом. Этот циркон идиоморфный или панидиоморфный, бесцветный, прозрачный. В виде оболочек он иногда нарастает на более ранние зерна минерала. В некоторых случаях цирконы ранней генерации лишь с одной стороны охвачены новообразованной оболочкой.

Цирконы из гранитогнейсов часто корродированы, метамиктны. Характерно присутствие различных наростов, «булавковидных» кристаллов (испытавшие преимущественный рост в одном направлении) и сростков из нескольких кристаллов.

Основная масса цирконов (до $80 \%$ ) из биотит - а фиболовы $\mathrm{x}$ гней сов (таблица, № 3) представлена панидиоморфными прозрачными или полупрозрачными кристаллами, слабоокрашенными в желтоватые тона. Довольно часто проявлена зональность, в большом количестве встречаются включения. Иногда заметны следы растворения на гранях кристаллов.

Можно выдвинуть предположение об образовании цирконов этого типа при региональном метаморфизме, конечным продуктом которого и являются изученные ортогнейсы.

В описанных архейских породах наиболее распространен метаморфогенный циркон. В биотит-амфибол-пироксеновых и двупироксеновых гнейсах и гранитогнейсах это панидиоморфные кристаллы, вершины и ребра которых носят явные следы окатывания. Такой циркон, согласно опубликованным данным, формируется при метаморфизме гранулитовой фации (Marshall, 1967). В этих породах нами отмечено еще наличие своеобразных «бесформенных» кристаллов циркона. В биотит-амфиболовых гнейсах распространены хорошо сформировавшиеся панидиоморфные кристаллы циркона (без ядер и наростов), свойственные для пород амфиболитовой фации. Для гранитогнейсов характерно присутствие наростов и «булавковидных» кристаллов.

С точки зрения исходной природы метаморфических пород представляет большой интерес наличие большого количества окатанных и полуокатанных зерен реликтового циркона в биотит-амфибол-пироксеновых и двупироксеновых гнейсах и гранитогнейсах, что позволяет поднять вопрос об их первично-осадочном происхождении, вместо обычно принятого (Кристаллический..., 1983) магматогенного генезиса.

\section{Нижнепротерозойские (свекофеннские) метаморфические породы}

Среди цирконов в а мфиболит ах (таблица, № 4) можно выделить два типа - реликтовые обломочные и более распространенные (до $60 \%$ ) цирконы, связанные с региональным метаморфизмом пород в условиях амфиболитовой фации (метаморфогенные цирконы).

Метаморфогенные цирконы встречаются как в виде отдельных бесцветных или светло-желтовато-бурых полупрозрачных и прозрачных кристаллов, так и в виде оболочек, нараставших на ядра различной формы. Для кристаллов характерна панидиоморфная форма. Внутренние изменения в цирконах данного типа выражены в виде помутнения; довольно часто в кристаллах проявлена зональность и прнсутствуют темноокрашенные включения.

Обломочные полуокругленные цирконы составляют до $30 \%$ от всех цирконов. Они светлоокрашенные, прозрачные и полупрозрачные; встречаются включения, зональность отсутствует. Обломочные зерна присутствуют также в виде ядер метаморфогенных кристаллов, а иногда сами содержат ядра еще более древнего циркона.

Иногда циркон в амфиболитах корродирован. 
В биотитовых пл агиогней с ах (таблица, № 5) циркон представлен панидиоморфными и полуокругленными полупрозрачными, иногда метамиктными, часто трещиноватыми кристаллами. Более или менее четко видна зональность, сравнительно много включений. Трещины в кристаллах нередко выполнены гидроокислами железа. Округленный циркон находится в незначительном количестве. Цирконы с ядрами не характерны.

Циркон из глиноземистых и биотитовых гнейсов (таблица, № 6) изучен в многочисленных разрезах Алутагузеской зоны, где эти породы очень широко распространены. Изученные породы претерпели метаморфизм в условиях высокой степени амфиболитовой фации.

Обнаружено, что циркон во всех образцах обладает тождественными свойствами. Выделяются две генерации минерала:

1) полуокругленные или округленные зерна, полупрозрачные или непрозрачные, коричневато-бурые, часто трещиноватые; содержат много включений, иногда заметна тонкая внутренняя зональность., Этот обломочный тип циркона встречается самостоятельными кристаллами и в виде ядер в более поздних цирконах;

2) панидиоморфные короткопризматические хорошо образованные кристаллы, прозрачные или полупрозрачные, часто мутные, корродированные. Самостоятельные зерна цирконов этого типа встречаются очень редко. Обычно они образуют оболочки на зернах первого типа, т. е. более ранней генерации. В некоторых случаях циркон из первой генерации лишь частично охватывается в состав зерна, образовавшегося позднее. Некоторые кристаллы несут следы коррозии.

Количество зерен циркона, несущих следы окатывания или содержащих окатанные ядра по отношению ко всей совокупности зерен, составляет $90-100 \%$.

Присутствие в указанных породах большого количества реликтовых окатанных зерен обломочного циркона является надежным признаком первично-осадочной природы этих метаморфических пород.

В нижнепротерозойских метаморфических пород a х важнейшими типами являются 1) панидиоморфный метаморфогенный циркон амфиболитовой фации, резко преобладающий в биотитовых плагиогнейсах, характерный (до $60 \%$ ) амфиболитам и имеющий подчиненное значение в глиноземистых гнейсах, 2) полуокругленный и округленный реликтовый обломочный циркон, резко преобладающй в глиноземистых гнейсах $(90-100 \%)$, характерный амфиболитам и отсутствующий в биотитовых плагиогнейсах. На этом основании плагиогнейсы могут быть отнесены к группе ортопород, остальные - к парапородам.

\section{Чарнокиты и мигматитобразующие граниты}

Характеристику цирконов чарнокитов (таблица, № 7) приводим по одному разрезу Южной Эстонии, где эти породы встречаются в виде относительно крупных ультраметагенных тел.

Преобладают кристаллы циркона панидиоморфной, призматической и близких к ним форм, реже встречаются полуокругленные и округленные зерна. В единичных случаях встречены зерна неправильной формы. Отмечается целый ряд зерен циркона с ядрами и выростами. По типоморфным особенностям различаются три разновидности (генерации) цирконов.

Циркөны первой генерации представлены полупрозрачными, иногда непрозрачными коричневатыми незональными трещиноватыми, часто с многочисленными микровключениями полуокругленными или округ- 
ленными зернами. Они образуют встречаются в виде ядер в зернах.

Цирконы второй генерации иногда образуют сростки или оболочки вокруг первых, но чаще встречаются в виде самостоятельных зерен без ядер. Кристаллы прозрачные нли полупрозрачные, с многочисленными включениями и трещинами. По форме преобладают панидиоморфные кристаллы, многие зерна с округленными вершинами, но с отчетливыми гранями призм.

Иногда распространяются еще цирконы третьей генерации, которые образуют наросты или оболочки вокруг зерен цирконов I и II генераций. Изредка циркон встречается также в виде отдельных крупных хорошо выраженных кристаллов. Последние, как правило, панидиоморфные или идиоморфные, коричневато-бурые, полупрозрачные.

Типоморфизм циркона гр ани т-м иг м а титов (таблица, № 8,9 ) изучен по ультраметаморфическим гранитоидам амфиболитовой (переходящей к гранулитовой) фации в пределах Йыхвиской и Тапаской зон. Гранит-мигматиты встречаются практически в разрезах всех скважин, образуя маломощные жилы (жильный материал мигматитов) или, редко, более крупные самостоятельные тела (плагиомикроклиновые граниты, микроклиновые граниты, плагиограниты). Участками мигматизация доходила до формирования обширных полей теневых мигматитов и гранитов. Однако по керну скважин нелегко в каждом конкретном случае провести тонкую классификацию мигматизирующего вещества.

Облик кристаллов циркона в гранит-мигматитах довольно разнообразен. Обычно цирконы представлены короткопризматическими и призматическими панидиоморфными кристаллами. Иногда преобладают полуокругленные и округленные цирконы или зерна неправильной формы. Поверхность многих зерен интенсивно корродирована. Цирконы чаще всего желтые и бурые, реже бесцветные. Характерны также темные полупрозрачные или непрозрачные мутные метамиктные кристаллы. Последние нередко обладают пониженным двупреломлением. В некоторых разновидностях гранит-мигматитов (теневый гранит, теневый мигматит) нередко присутствуют кристаллы прозрачного циркона с округлым ядром более темноцветного циркона. Зерна часто разрушены многочисленными трещинами. Для теневых гранитов и плагиомикроклиновых гранитов особенно характерны выросты, изредка сростки из двух цирконов. Зональность широко распространена в плагиоклазовых гранитах. Цирконы часто содержат мельчайшие буро-черные включения, очевидно рудных минералов. Реже встречаются газово-жидкие или игольчатые включения. Мутность и метамиктность кристаллов часто затрудняет обнаружение включений и зональности.

Из рассмотренных примеров видно, что в зависимости от особенностей циркона ультраметагенные гранитоиды можно разбить на несколько групп.

Значительный интерес представляет циркон тен евого мигм а т и та (таблица, № 8) разреза скв. Ф-164 (Тапаский блок). Этот разрез, видимо, представлен метаморфизованными и мигматизированными ортопородами. Считается, что формирование жильного материала мигматита происходило путем мобилизации легкоплавкого субстрата при анатексисе и метасоматозе. Цирконы в описываемых породах в преобладающем большинстве полуокругленной и округленной формы, прозрачные, чаще всего желто-бурого или коричневого цвета. Ядра, зональность и наросты отсутствуют, сростков не наблюдается. Цирконы подобной формы не позволяют их рассматривать реликтовыми первично-осадочными образованиями (Дамаскина, 1973). Причину 
появления цирконов подобного вида в исходных метаморфических породах можно объяснить (Норре, 1966) а) их ростом в стесненных условиях процесса метаморфизма; б) коррозией кристаллов, содержащихся в породах габбрового или диоритового состава, которые подвергались метаморфизму. В данном случае нам более реальным видится последнее объяснение, так как исходными породами обоих изученных разрезов были, видимо, магматические породы основного или среднего состава.

Довольно часто встречаются еще неправильные или корродированные зерна циркона.

Теневые граниты; теневы е мигм атиты (таблица, № 9, Иыхвиский блок). Циркон характеризуется преобладанием панидиоморфных призматических разновидностей (до $85 \%$ ). Кристаллы часто трещиноваты, трещины нередко выполнены гидроокислами железа. Благодаря густой сети трещин они становятся полупрозрачными или, реже, непрозрачными. Довольно часто встречаются включения, зональность наблюдается слабо. Характерной особенностью цирконов этого типа является присутствие на некоторых из них разноориентированных выростов. Изредка встречаются агрегаты зерен и сростки. Довольно часто на окатанных зернах циркона образованы оболочки - это т. н. циркон с ядрами. Полуокругленные и округленные формы циркона наблюдаются как в виде ядер, так и в виде самостоятельных кристаллов. Они представлены полупрозрачными коричневато-бурыми, часто трещиноватыми зернами, содержат включения, нередко ядра.

Наличие в граните большого количества окатанных (реликтовых) кристаллов и панидиоморфных (идиоморфных) кристаллов циркона с окатанными ядрами и выростами на них указывают на его метасоматический генезис. Наличие окатанных цирконов позволяет предполагать, что исходной породой, подвергшейся метасоматическому изменению, могли быть парагнейсы - вышеописанные глиноземистые гнейсы.

В плагиогранитах (таблица, № 10) преобладают панидиоморфные бесцветные полупрозрачные или прозрачные, часто трещиноватые кристаллы, лишенные зональности и включений, возникновение которых, вероятно, связано с метасоматическими процессами. Реже распространяются панидиоморфные полупрозрачные корнчневатые кристаллы с четкой зональностью. Такие цирконы образовались, по-видимому, при региональном метаморфизме (Вайтекунас, Васильев, 1975). В плагиогранитах содержание полуокругленных цирконов доходит до $25 \%$ от общего его количества в породе. Они представлены полупрозрачными мутными зернами. Содержат много включений. Иногда они встречаются ядрами в панидиоморфных зернах.

В плагиомикроклиновых гранитах (таблица, № 11) циркон представлен двумя типами с резким преобладанием панидиоморфного призматического циркона (до 75\%). Цвет бурый, реже желтый или бесцветный. Часто кристаллы циркона непрозрачны за счет обильной трещиноватости (трещины выполнены бурыми гидроокислами железа). В большом количестве встречаются включения. Ядра отсутствуют. Зональность развита очень слабо, или вовсе отсутствует. Характерны выросты. Содержание полуокругленного циркона до $25 \%$. Зерна его полупрозрачные, коричневато-бурые, трещиноватые, содержат ядра.

Циркон гранитоидного мигм а ти тобразующего вещ е с т в а крайне интересен для выяснения генезиса этих пород. Реликтовый окатанный обломочный циркон изученных чарнокитов, теневых гранитов и мигматитов, плагиогранитов указывает на первично-осадочное происхождение мигматизированных метаморфических пород. В этой связи 
интересно малое количество обломочного циркона в плагиомикроклиновых гранитах. Во всех описанных типах пород распространены метаморфический панидиоморфный циркон, а также метасоматические наросты и оболочки (особенно в чарнокитах) на нем.

\section{Интрузивные послескладчатые граниты}

Свойства циркона порфировидных калиевых гранитов (таблица, № 12) рассмотрены на примере пород Неэмеского массива.

Магматогенные цирконы характеризуются четким идиоморфизмом зерен и совершенной огранкой призматических панидиоморфных кристаллов. Кристаллы бесцветные или бледноокрашенные, прозрачные, редко полупрозрачные, содержат в большом количестве разнообразные включения; широко проявлены зональность и трещиноватость. Поверхность граней гладкая, иногда слабошероховатая со ступенчатыми следами роста, часто испытавшими преимущественный рост в одном направлении, образовав т.н. булавковидные кристаллы. Новообразование циркона проявляется слабо - наблюдаются выросты на реликтовых кристаллах. Некоторым цирконам присущи изменения, связан ные с возможным автометаморфизмом: кристаллы подвержены помутнению по зональности и трещинам. Прощесс растворения проявлен слабо, корродированных зерен сравнительно мало.

Свойства цирконов рапакиви -гр анитов (таблица, № 13) рассмотрены на примере проб из пород Рижского плутона. Циркон рапакиви-гранитов отличается своей совершенно правильной формой кристаллов. Присутствуют идиоморфные и близкие к ним панидиоморфные призматические или длиннопризматические кристаллы. Преобладающие удлинения имеют широкий максимум - от 1,5 до 4,0, нередко и больше. Циркон присутствует, как правило, в виде бесцветных или светлоокрашенных прозрачных кристаллов, реже встречаются густоокрашенные кристаллы, нередко обладающие пониженным двупреломлением. Зональность отсутствует или выражена слабо. Часто встречаются сложные уплощенные, как будто сросшиеся кристаллы. Некоторые зерна трещиноваты, корродированны.

В послескл адч атых гр ан и ах резко преобладает идиоморфный или панидиоморфный циркон, являющийся признаком магматогенного генезиса породы (Вайтекунас, Васильев, 1975).

\section{Заключение}

Подытоживая вышеизложенное, следует отметить, что циркон в разных типах изверженных и метаморфических пород кристаллического фундамента имеет существенные различия в морфологии и во внутреннем строении, являясь таким образом хорошим руководящим акцессорным минералом. В одних и тех же породах могут содержаться цирконы различного генезиса, но в каждой из разновидностей пород какой-то один тип циркона количественно преобладает над остальными, позволяя использовать индикаторные свойства для решения разных геологических проблем.

К настоящему времени исследована лишь часть комплексов, групп и типов пород. Исследование всех типов пород фундамента представляет интерес для полной его характеризации, в частности для решения генетических вопросов кристаллических пород. Как указано выше, результаты исследования циркона в общем подтверждают сложившееся представление о генезисе пород. Однако, интерес представляют и отклонения от подтвердившегося представления о наличии, напри- 
мер, обломочных цирконов в архейских пироксеновых гнейсах, считавшихся первично-вулканогенными. Одновременно специфика типоморфизма циркона в разных породах фундамента позволяет выдвинуть вопрос о поисках источника циркона базальных отложений платформенного чехла. Тесное чередование в разрезах кристаллического фундамента разных по составу (кислые, средние, основные, глиноземистые) и генезису (метаморфические, метасоматические, магматические) пород, совместное нахождение в каждой нескольких типов и генераций циркона (реликтово-осадочный, магматогенный, метаморфогенный, метасоматический) и морфологическое их разнообразие все же осложняют решение конкретных вопросов унаследованности минерального состава осадочного чехла от фундамента. Можно предположить, что заметные отклонения в составе и типоморфизме акцессорных минералов базальных слоев чехла могут быть связаны только с крупными массивами интрузивных гранитондов.

\section{ЛИТЕРАТ У Р А}

Вайтекунас А. К., Васильев В. А. Акцессорные минералы пород докембрия Южной Прибалтики. - Тр. АН ЛитССР. 1975, вып. 28, 89-94.

Вийдинг Х., Конса М. Учет данных по типоморфным разновидностям минералов терригенных отложений. - В сб.: Методика и интерпретация результатов минералогических н геохимических исследований. Вильнюс, 1976, 60-67.

Дамаскина $\Gamma$. Д. Морфологическне типы цирконов в гранитондах гранулитовой фации Алданского щита. - В сб.: Петрология гранулитовых фаций Алданского щита. М., 1973, 163-171.

Конса М. Н., Вийдинг Х. А. Проблемы унаследованности минерального состава терригенных отложений (на примере сравнительного изучения коры выветривания кристаллического фундамента и базальных осадочных пород). - В сб.: Терригенные минералы осадочных пород Прибалтики. Таллин, 1983, 41-49.

Краснобаев А. А., Сплошнова Н. С. О некоторых морфологических особенностях кристаллов акцессорного циркона. - В сб.: Минералогия и минералогическая кристаллография. Свердловск, 1971, 85-89.

Кристаллический фундамент Эстонии. М., 1983.

Ляхович В. В. Акцессорные минералы горных пород. М., 1979.

Hoppe, G. Zirkone aus Granuliten. Ein Beitrag zum Granulitproblem. - Ber. Dtsch. Ges. geol. Wiss., Min. und Lagerst., 1966, 11.

Marshall, B. The present status of zircon. - Sedirrentology, 1967, 9, N 2, 100-103.

Институт геологии

Академии наук Эстонской ССР
Поступила в редакцию

$7 / 11985$

Mare KONSA

\section{TSIRKOONI TUPOMORFSED ISEÄRASUSED EESTI KRISTALSES ALUSKORRAS}

Artiklis on iseloomustatud tsirkooni tüpomorfismi kristalse aluskorra erinevates kivimitüüpides. On leitud tsirkooni tüpomorfseid tunnuseid, mis aitavad määrata aluskorra kivimite geneesi ja settekivimite basaalkihtide pärandatavust.

Mare KONSA

\section{TYPOMORPHIC VARIATIONS OF ZIRCON IN THE CRYSTALLINE BASEMENT OF ESTONIA}

The author presents the characteristics of the typomorphic variations of zircon in the more frequently distributed metamorphic, metasomatic and igneous rocks on the southern slope of the Baltic Shield.

The results of the study show that the typomorphic features of zircon may be of use for elucidating the heredity of the above-lying Vendian and Cambrian clastic material. At the same time the genesis of the same crystalline basement rocks may also be determined with the help of the typomorphic characteristic features of zircon. 